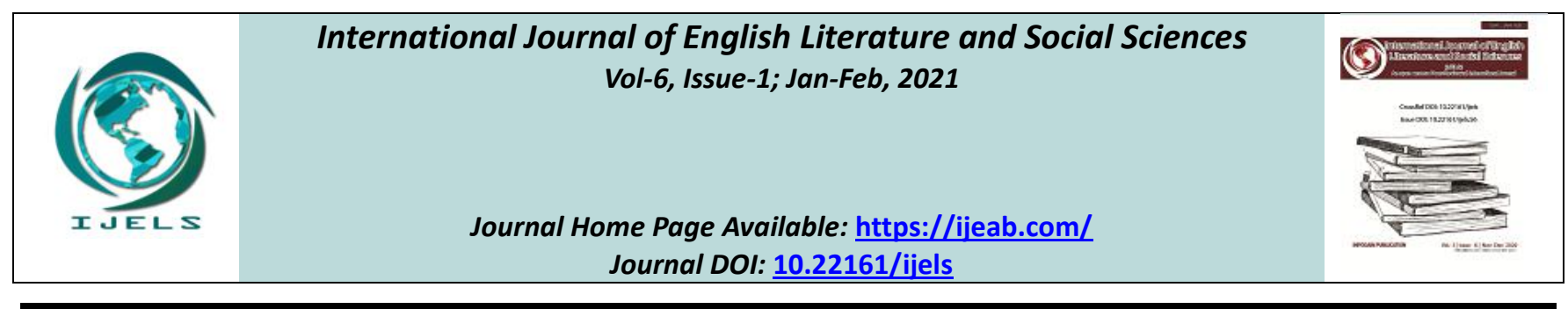

\title{
Investment Risk, Information Disclosure, and Market trust-Based on trust game experiment research
}

\author{
Fu Xin ${ }^{1}$, Zhang Yun ${ }^{2}$
}

School of International Economics and Trade, Central University of Finance and Economics, Beijing, China

School of Finance, Shanghai University of Finance and Economics, Shanghai, China

Received: 18 Nov 2020; Received in revised form: 21 Dec 2020; Accepted: 01 Jan 2021; Available online: 07 Jan 2021

C2021 The Author(s). Published by Infogain Publication. This is an open access article under the CC BY license

(https://creativecommons.org/licenses/by/4.0/).

\begin{abstract}
This paper studies the influence of investment risk and information disclosure on market trust by extending the classic trust game experiment. First of all, the investment trust experiment with no investment risk and investment risk was conducted respectively, then by introducing investment-related information study the game problem of market investment trust. The results show that, the uncertainty risk of investment returns will significantly reduce the level of mutual trust among participants in the investment market and Inhibit investment. At the same time, the impact of such income uncertainty is heterogeneous. In the case of higher income level, risk has less inhibitory effect on investment, while in the case of lower income level, risk has greater inhibitory effect on investment. Investment-related information disclosure can improve market trust, and more importantly, it can effectively reduce the adverse impact of investment risks on market trust. Therefore, in the process of continuous improvement of the capital market, the establishment of a standardized information disclosure mechanism and the reduction of information asymmetry can reduce the impact of risks on the market and give play to the function of the capital market in the efficient allocation of funds.
\end{abstract}

Keywords - Market trust, Experimental study, Investment risk, Information disclosure.

\section{INTRODUCTION}

With the gradual improvement of China's market economic mechanism, the market has become a decisive way of resource allocation. Market economy is a credit economy, and trust is an important cornerstone for giving play to the role of the market (Arrow, $1974^{[1]}$ ).Market trust is considered as another important social capital that determines a country's economic growth in addition to material capital and human capital (Zhangand
$\left.\mathrm{Ke}, 2002^{[2]}\right)$. The rapid transformation of Chinese society has brought profound changes in economic, political and cultural fields, and market trust can reflect and adjust many problems and conflicts in economic society (Zhao et al. ${ }^{[3]}$ ).A good relationship of market trust is an important guarantee for the normal operation of modern economy and finance, giving play to market efficiency and risk.As an input factor of social and economic development, trust has positive externalities, and the sharing behavior related to 
trust can obtain better economic consequences (Fukuyama,1995 ${ }^{[4]}$;Putnam,1993 ${ }^{[5]}$ ).Market trust promotes economic growth and financial development (Portaetal.,1997[6];Guiso et al.,2004[7]), but also affect the investment and financing decisions of micro enterprises (Dai et al.,2009 ${ }^{[8]}$;Panet al.,2009 ${ }^{[9]}$ ).As an important regulating force in economic operation, the lack of market trust will bring negative impact on the whole social and economic development, and the impact of the lack of trust will spread quickly in a short time.Therefore, in order to realize the full and effective allocation of economic resources by the market, it is necessary to constantly improve the relationship of market trust and enhance the level of market trust.

However, trust in the market is very fragile, vulnerable to a variety of adverse factors, and once lost, the cost of restoring trust in the market can be very high.China's current market economy is still in the process of continuous improvement, the economic system is not perfect, so in the process of economic operation of fraud, fraud and other different types of risks have a huge impact on the trust relationship in the market.The stable development of the whole market economy is not only related to the basic business performance of the company, but also related to the reasonable expectation of market participants for future development and market confidence (Zhang and Chen, $\left.2002^{[10]}\right)$. When the investment risk increases, it will seriously damage the investor's confidence, thus reducing the trust relationship of the whole market and inhibiting the reasonable allocation of resources. Without the support of trust, the market will fall into chaos and disorder, which may trigger systemic risks and even undermine social stability.

An important reason for market risk is the asymmetry of information. The stable operation of the contemporary market economy cannot do without a good environment for information dissemination, and the investment market is highly dependent on information. Although the development of modern social science and technology has created favorable conditions for the transmission of information, in many cases, the access to information is still limited by various conditions. Such information asymmetry is determined by the shared characteristics of information. As a kind of quasi-public goods, information is highly competitive, and individuals need to pay a high cost to obtain information. In addition, in the process of information transmission, from the information source to the information user, the information will objectively occur in the time delay and information content leakage.Information intermediaries in the market have the responsibility to identify and identify the authenticity, accuracy and integrity of information. However, with the lack of credit of a large number of individual companies, more and more problems of lack of trust are exposed.

Therefore, the market economy is actually the economy of the information market. The timeliness, accuracy and comprehensiveness of information disclosure are the foundations of public trust in the whole market economy. Information asymmetry is an important reason for the lack of market trust.The level of trust in the investment market is directly affected by the transparency of market information.In order to ensure the stability of market trust, realize the function of market capital formation and effective allocation, and then play the regulating role of market to the growth of the whole national economy, the key problem to be solved is the problem of market information. That is to say, in order to ensure that the market price accurately and timely reflect the operating conditions and risks of each company, individual companies and the overall market need to improve the information disclosure mechanism. Under this premise, capital holders can combine their own risk appetite, reasonably anticipate the future, and are willing to invest funds to target enterprises.On the contrary, when information asymmetry increases, investors cannot accurately predict the future and their investment intentions decline.Similarly, in the case of full disclosure of information, enterprises can obtain reasonable capital input, financing costs and operational risks are consistent, and enterprises can make better use of capital advantages and realize effective allocation of resources.Only under the premise of effective disclosure of information, the government and regulatory authorities can find problems in a timely manner, protect the rights and interests of all parties, and effectively prevent the occurrence of market systemic risks.

Therefore, the research on the relationship between investment risk and information disclosure and market trust 
plays a vital role in giving play to the function of market resource allocation and maintaining social and economic stability. The existing literature has carried out some studies on the impact of risk on trust, but there is still little discussion on the regulatory function of information disclosure on risk and trust.An important reason is that it is very difficult to obtain data such as trust, risk measurement and information measurement in the existing social economy. Moreover, even if a good alternative variable is selected to study the problem, there are serious endogenous problems among all variables and it is difficult to explain the mutual causal relationship.Therefore, through the classic trust game experiment and the scientific experimental conditions, this paper studies the causal relationship between the three in order to provide some theoretical support for the market trust problem.Compared with the previous research results, the contribution of this paper is as follows: First, through systematic and scientific trust game experiment, it is verified that the risk of uncertain returns reduces the trust of investors and weakens the capital market capital allocation efficiency, providing scientific proof for the existence of this problem.Secondly, the paper conducts an experimental study on the disclosure of investment-related information, proving that the disclosure of information can improve the trust level of investors and enhance the market activity.Finally, this paper finds that the full disclosure of information can effectively reduce the adverse impact of investment risk, and provide a scientific theoretical basis for the solution of this problem. The rest of this paper is arranged as follows: The second part is theoretical analysis and research hypothesis;The third part is the research design;The fourth part results analysis; The fifth part is the main conclusion.

\section{LITERATURE REVIEW AND RESEARCH HYPOTHESIS}

The earliest and most famous research on social trust is the trust game experiment of Berg, Dickhaut and Mccabe(1995) ${ }^{[11]}$, which proves the existence of trust and indicates that trust is an important starting point for economic and social development.Along the train of thought of Berg, Dickhaut and Mccabe (BDM for short, the same below), many scholars have carried out extensive research on the influence of factors on trust from different
perspectives.Johansson et al. (2008) ${ }^{[12]}$ found that people's initial endowment of funds would have an impact on people's trust level in the economy.Cameron(1999) ${ }^{[13]}$ drew a different conclusion that endowment of funds would not change public trust behavior (Fehr et al. 2002 ${ }^{[14]}$; Li Bin et al., 2015 $\left.5^{[15]}\right)$. The size of investment returns also has an impact on investors' trust, and different growth rates will affect trustors' decision-making behaviors when considering their investment (Coleman, 1990 ${ }^{[16]}$;Bolle $1990^{[17]}$;Bottom, $\left.1998^{[18]}\right)$. At the same time, when the identity of the investor is unknown, investors will show lower trust (Sanfey et al. 2003 ${ }^{[19]}$;Bottom et al. 2006 ${ }^{[20]}$ ).In addition, the intensity of government control in a country (Aghion et al. 2010 ${ }^{[21]}$ ), cultural differences and gender differences (Slonim and Guillen, 2010 [22]) all affect the public's market trust.Therefore, the factors that affect market trust are numerous and complex, and trust is easily impacted by various factors. Therefore, it is of great importance to study the factors that can have the most significant impact on trust.Among them, the impact of various types of risks on trust is one of the most important reasons, which needs to be further studied.

\subsection{The impact of risk on trust}

Reviewing the development history of China's market economy, events leading to market trust crisis are common. From financial fraud of listed companies to non-disclosure or delayed disclosure of problematic information of companies, a series of risks have a huge impact on investor trust, and market trust is constantly destroyed.External risks of economic environment will have an impact on social trust and reduce the level of social trust ( $\mathrm{Li}$ et al.,2015 ${ }^{[15]}$ ). Uncertainty of economic environment will affect the investment rate, and the degree of characteristic risk inhibiting investment will increase with the increase of risk (Liet al., 2018 ${ }^{[23]}$ ).Li et al. (2017) ${ }^{[24]}$ studied the relationship between bank operation risk and market trust, and found that the two are mutually causal. The increase of risk will reduce depositor trust, and the decrease of trust will further increase bank risk through the fluctuation of return on assets.Chen et al. (2014) ${ }^{[25]}$ also studied the impact of perceived risk in online lending on trust, and the increase of perceived risk will significantly affect trust and reduce lending willingness. At the same time, risk changes will also have an impact on consumer trust, and increased risks will 
reduce consumers' purchase intention (Pan et al., $\left.2010^{[26]}\right)$.Liuet al.(2016) ${ }^{[27]}$ studied the internal relationship between stock price crash risk and regional social trust. The higher the level of social trust in the region where the listed company is located, the lower the risk of the company's stock price crash in the future.Li and Yang(2015) ${ }^{[28]}$ studied the impact of risks on enterprise investment from the perspective of economic policy uncertainty, and when uncertain risks increase, enterprises' investment will be inhibited.Liu and $\mathrm{CaO}(2017)^{[29]}$ found that the risk of economic uncertainty would reduce the investment efficiency of enterprises through the increase of credit.Based on the research of domestic and foreign scholars on the impact of different risks on different levels of trust, this paper believes that investment risks in the market will also have an adverse impact on investors' trust and affect their investment intentions. And the uncertainty risk of income will have heterogeneity because of the size of investment income.Therefore, this paper proposes the following research hypothesis:

Hypothesis 1a: In the process of market investment, the uncertain risk of returns will significantly reduce investor trust and inhibit investment;

Hypothesis 1b: The higher the investment return, the smaller the impact of uncertainty risk on investment trust, and the lower the return, the greater the impact of uncertainty risk on investment trust.

\subsection{The moderating effect of information on risk} and trust

Resource allocation market is actually an information market, and timely and accurate information disclosure is an important cornerstone for the establishment of investment market trust. Since the 1990s, a large number of scholars have conducted research on the impact of listed company information disclosure on the market. Existing research opinions generally believe that the information disclosure of listed companies can help reduce information asymmetry and potential investment risks, thereby affecting the cost of capital and stock prices of listed companies. An empirical study of listed companies at home and abroad found that the higher the quality of a company's information disclosure, its financing costs and bond financing costs will be significantly reduced (Botosan,
1997 ${ }^{[30]}$; Botosan et al., 2002 ${ }^{[31]}$; Sengupta, 1998 ${ }^{[32]}$; Wang Wei et al., 2004 ${ }^{[33]}$ ), listed companies with different levels of disclosure also have significant differences in the market liquidity of their stocks. The higher the level of disclosure, the smaller the bid-ask spread, the higher the liquidity of listed companies (Zhanget al., 2007 ${ }^{[34]}$ ). Since there are analysts in the market, the uncertainty of listed companies and analysts can be reduced by collecting information on listed companies. When listed companies take the initiative to disclose information, analysts will provide investors with more efficient investment advice (Botosanet al., 2004 ${ }^{[35]}$ ), in order to enhance their market recognition, analysts are more inclined to chase listed companies with higher levels of information disclosure to ensure that their forecast errors are less volatile (Lang et al., 1996 ${ }^{[36]}$ ).

However, establishing and ensuring the timely, accurate, and comprehensive information disclosure in the market is a long-term and complex systematic project. It is precisely because of the lack of information that many risks appear, which seriously affect the trust relationship in the market. This is usually due to the limited rationality of market entities, the existence of market transaction costs, and the occurrence of a large number of accidental factors, which often produce information asymmetry. Asymmetric information of information will lead to adverse selection by market participants. Investees have a clearer understanding of their own operating conditions, product quality standards, and capital allocation risks, etc., while investors are more difficult to obtain. Real information leads to an increase in the investment risk of investors and a decline in investment willingness. And the greater the degree of information asymmetry, the higher the information cost of investors in the market and the greater the transaction costs, the more likely it is to generate moral hazard. When the information asymmetry becomes more serious, the related party transactions and insider trading are more prevalent in the market, the market efficiency will be lower, and the resource allocation function of the market will be more limited. Only by fully disclosing the information of all parties in the market and reducing the information asymmetry between investors and investees can information have a good trust relationship and give full play to market functions.

Therefore, the key to supporting market trust 
relationships, reducing investment risks, and giving full play to the function of market resource allocation is adequate information disclosure, reducing information asymmetry, and making prices fully reflect the company's operating conditions and existing risks. Only under this premise can fund holders choose investments that meet their own risk preferences and expected returns. At the same time, the investee company can also get the corresponding resource allocation, while reducing market risks, it achieves the goal of effectively allocating resources in the market. You et al.(2007) ${ }^{[37]}$ found that the information of a listed company represents its characteristics. The lower the degree of disclosure of a company, the higher the synchronization between its stock price and the market index. The detailed disclosure of financial audit opinions by listed companies can effectively reduce investor confidence and increase investment willingness. Strengthening the disclosure of corporate auditing and internal control is of positive significance for improving investors' investment decision-making (Zhanget al., 2011 ${ }^{[38]}$ ). Wang et al. $(2018)^{[39]}$ found through the operation of online loan platforms that the more information disclosed on the platform, the easier it is to attract investors to participate in transactions and increase transaction volume. At the same time, this information disclosure can reduce the investment risk of investors. Therefore, the prediction results of the ratio of information disclosure to investment in this article also change positively, and this positive effect on trust can reduce the adverse impact of risk. The following assumptions are proposed:

Hypothesis 2a: Disclosure of investment information can effectively improve investor trust in the market;

Hypothesis 2b: The more information disclosed, the higher the level of investor trust;

Hypothesis 2c: Information disclosure can effectively reduce the adverse impact of uncertain risks on investment trust.

\section{RESEARCH DESIGN}

For the research on investment risk, information disclosure and market trust, on the one hand, the results are limited because of the obstacles of data acquisition. Trust is a subjective feeling of economic man, and objective and accurate measurement is itself a very difficult problem. On the other hand, even if the data is obtained, it is difficult to identify whether it is a risk factor or other factors that have caused a change in trust. It is even more difficult to identify how information regulates the impact of risk. Therefore, this paper uses the classic trust game experiment designed by Berg, Dickhaut, and McCabe (1995) ${ }^{[11]}$ to change different experimental conditions, more accurately control the influence of different factors, and study the problems of risk, information and information.

\subsection{Experiment design}

(1) Experiment introduction. In the investment game experiment in this article, the experimental process is shown in Figure 1. At the beginning of the experiment, investor $\mathrm{A}$ is provided with initial funds of $\mathrm{W}_{\mathrm{i}}$ units, and $\mathrm{i}$ represents each investor. Investor B has no initial funds, and both parties of the transaction proceeded anonymously during the entire experiment. These initial conditions of the investor and the investee are known in the experiment. In the first stage, investor A decides how much money to invest in investee B. Assuming that the investment ratio is $\alpha_{i}$, the investment amount is $\alpha_{i} * W_{i}$. When the investment funds reach the invested $B$, the funds will become $\mathrm{R}$ times. Therefore, when the funds reach the invested $\mathrm{B}$ are $\mathrm{R} * \alpha_{i} *$ $W_{i}$. In the second phase of the experiment, Investee $\mathrm{B}$ decides to return the proportion of $\beta_{i}$ to Investor $\mathrm{A}$. The amount of return is $\beta_{i} * \mathrm{R} * \alpha_{i} * W_{i}$, among which $\alpha_{i}$ and $\beta_{i} \in[0,1]$. This round of investment experiment is over. Perform the next round of experiments under the same conditions until the end of this type of experiment. After each round of experiment, the wealth of investor A and invested $\mathrm{B}$ are:

$$
\begin{gathered}
P_{a i}\left(\alpha_{i}, \beta_{i}\right)=\mathrm{W}_{\mathrm{i}}-\alpha_{i} * W_{i}+\beta_{i} * \mathrm{R} * \alpha_{i} * W_{i} \\
P_{b i}\left(\alpha_{i}, \beta_{i}\right)=\mathrm{R} * \alpha_{i} * W_{i}-\beta_{i} * \mathrm{R} * \alpha_{i} * W_{i}
\end{gathered}
$$

Given the indirect utility function $V_{j i}\left(P_{j i}\left(\alpha_{i}, \beta_{i}\right)\right)$, where $\mathrm{j}=\mathrm{a}, \mathrm{b}$. Both investor $\mathrm{A}$ and invested $\mathrm{B}$ need to maximize their respective utility, and the utility function is an increasing function of wealth. When there is no trust $\alpha_{i}$ and $\beta_{i}$ must be zero, but the BDM experiment proves that trust exists in society and can play an important role. Investors and investees will choose a way that $\alpha \_i$ and $\beta \_i$ are greater than zero to maximize their utility. At the same time, in the BDM experiment, the investor ratio $\alpha_{i}$ is used 
as an indicator to measure the degree of trust in society. This article also draws on this idea, and at the same time measures the investor market from the two dimensions of the investor's investment ratio $\alpha_{i}$ and the investor's return ratio $\beta_{i}$ Then we study the influence of investment risk and information disclosure on the investment ratio $\alpha_{i}$ and return ratio $\beta_{i}$, that is, the impact on investment trust.

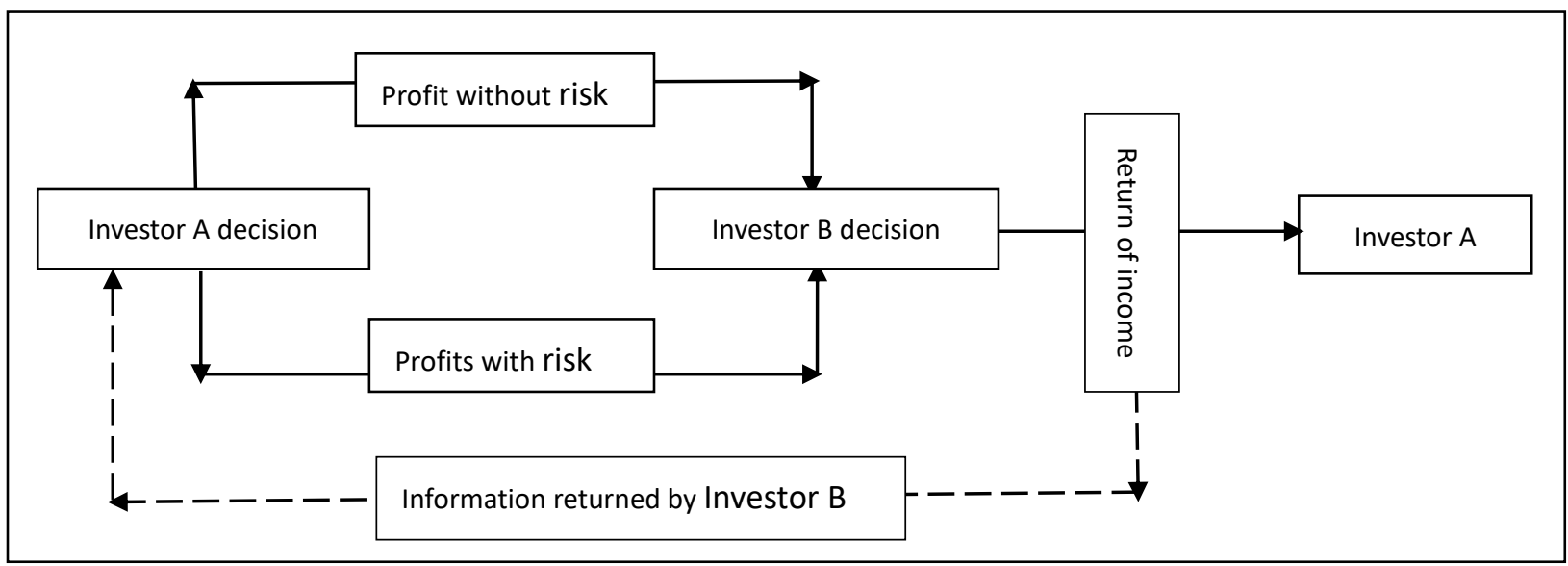

Fig.1: Introduction to the investment game experiment process

(2) Experiment process.In order to study the impact of investment risk and information disclosure on investment market trust, this article first conducts an experiment on the impact of investment risk on market trust, and then changes the conditions to conduct experiments when there is information disclosure. Fehr et al. (2002) ${ }^{[14]}$, Li Bin et al. (2015) ${ }^{[15]}$ proved that the scale of assets to be invested does not change the investment ratio of trustees. This article sets the initial capital of investor A to be 10 yuan in each round of experiment For follow-up experiments. Regarding whether there are risks in the investment process (Figure 1 above), first conduct an experiment without investment risk, that is, the return is risk-free. Investor A makes a decision to invest a certain amount, and the return is confirmed to triple to reach the investee $B$, Investee $B$ decides how much income to return to investor $\mathrm{A}$. In this paper, $\mathrm{R}$ is three times when there is no risk, and when the return is risky, $\mathrm{R}$ is 0 times, 3 times, and 6 times with one-third probability. After the completion of the control experiment with the investment return of 3 times, the experiment with investment risk is carried out. The investment risk is that when investor A decides how much to invest, the investment will become 0 with a probability of one-third. The original investment 3 times of the original investment and 6 times of the original investment reach Investor B. Investor B makes a decision to return the income and decides how much income to return to Investor A. In the course of this experiment, the investment amount is determined by the risk-free 3 times and the risky with a one-third probability of 0,3 , and 6 times. In each round of the experiment, the investor and the investee know exactly . But when there is investment risk, the amount invested by investor $\mathrm{A}$ is not clear to investee $\mathrm{B}$, and the amount of amount that reaches investee $\mathrm{B}$ is also unknown to investor A. For example, when the investee $B$ receives an investment with an amount of 0 , he does not know whether the investor did not invest at the beginning of the period, or did the investment but the risk return has become 0 . Similarly, for Investor A, when he invests an amount greater than 0 and receives a return amount of 0 from the investor, the investor does not know whether the investor has the return but did not return it, or it was originally caused by risk The income is 0 and cannot be returned.

In the research on the impact of information disclosure on market investment trust, this article analyzes the investment information based on the above-mentioned classic experiments. The specific information is the impact of the information on the amount returned by Investor B to the investor and the information on whether the counterparty is fixed on investment trust. Returning information refers to when the investor makes an investment decision, it is multiplied by the corresponding multiple and the income reaches the investee $\mathrm{B}$. At this time, 
the investor decides how much to return to the investor. Before the start of each round of experiments, whether investor A can see the previous round of return amount information of investee B for a comparative study, as shown by the dotted line in Figure 1 above, the return information reaches the investor to influence the next round of experimental decision-making. There is another type of information in the investment experiment, that is, the information of the fixed counterparty. It is a type of experiment that is randomly matched at the beginning of the experiment to form a group of investors and investees, and trade in multiple rounds in this same type of experiment. The counterparty is fixed, and both parties to the transaction know this information. At this time, the investor will not only know the amount information returned by the investor in the previous round of the experiment, but also know the counterparty information in the current round of the experiment, which has a stronger information content. Therefore, in order to study the marginal effect of information on investment trust, this paper conducts investment experiments of the non-information group, the low-information group and the high-information group according to the information content of different types of experiments. Specifically, in the experiment, the group that exchanged the experimental counterparty and did not know the information returned by the investor in the last round was the non-information group, and the group that exchanged the experimental counterparty but the investor knew the information returned by the investor in the previous round was the low-information group. Know the return information and also know that the counterparty information is the high information group. The specific grouping is shown in Table 1 below.

Table 1 Experimental classification of investment trust game

\begin{tabular}{|c|c|c|c|}
\hline & & Without Risk & With Risk \\
\hline \multirow{3}{*}{$\begin{array}{l}\text { Information } \\
\text { content } \\
\text { from low to } \\
\text { high }\end{array}$} & $\begin{array}{c}\text { No } \\
\text { information } \\
\text { group }\end{array}$ & $\begin{array}{l}\text { First: Competitor exchange, no } \\
\text { return information, no risk }\end{array}$ & $\begin{array}{c}\text { Second: Competitor exchange, } \\
\text { no return information, risk }\end{array}$ \\
\hline & $\begin{array}{c}\text { Low } \\
\text { information } \\
\text { group }\end{array}$ & $\begin{array}{l}\text { Third: Competitor exchange, } \\
\text { return information, no risk }\end{array}$ & $\begin{array}{c}\text { Fourth: Competitor exchanges, } \\
\text { return information, and risk }\end{array}$ \\
\hline & $\begin{array}{c}\text { High } \\
\text { Information } \\
\text { Group }\end{array}$ & Fifth: Fixed opponent, no risk & Sixth: Fixed opponent and risk \\
\hline
\end{tabular}

Note: According to whether there is a risk and the information content is divided into six types of experiments from low to high, the following types of experiments represent experiments under different conditions.

(3) Experimental deviation control.Due to the particularity of experimental research, it is easy to be affected by the social relationship between experimental participants and the independence of experimental results. This article fully controls the anonymity in the experiment. When the experiment starts, each experimental participant is randomly assigned a role, And it is impossible to know the personal information of the experiment opponent, through this anonymous control to maintain the independence and objectivity of the experiment. At the same time, the information exchange is controlled during the experiment. During the entire experiment, when the experiment starts, the experimental participants are assigned to an independent experimental area, and all communication tools are cut off to ensure that no strings are formed between participants during the experiment. Seek cooperation to influence the results of the experiment. In addition, in order to control the influence bias caused by the first investment and the limited game, each type of experiment was carried out 1, 6, and 12 repeated experiments, and the results of the intermediate rounds of the multiple rounds of experiments were selected for problem research.

\subsection{Main variables}


(1) Market trust. As a dependent variable, it is very difficult to identify and measure market trust in the investment market. This article draws on the methods of BDM and other documents to measure the investor's investment ratio Invratio ${ }_{i t}$ and the investor's return ratio Retratio $_{i t}$ from two dimensions. Trust. Among them, Invratio $_{i t}$ is the ratio of the investment amount selected by the $\mathrm{i}$-th investor in the $\mathrm{t}$-round investment experiment to the total amount, and Retratio ${ }_{i t}$ is the amount returned to the investor by the $\mathrm{i}$-th investor in the t-round experiment as a percentage of the amount received The proportion of the amount.

(2) Investment risk. Influencing market trust in the market will be affected by various types of investment risks, but among the many investment risks, the risk of uncertainty in return has the greatest impact on investment trust and the most profound impact on trust. Therefore, this article uses the uncertainty risk of return as a measure of investment risk to study the impact of risk on market trust. In the experiment, the return risk is measured by changing the return conditions. The return has no risk, that is, the return is three times the certainty, and the return is risky. The probability of one-third is zero, three and six times. That is, the return risk Risk $_{i t}$ is a dummy variable, which is 1 when there is a risk, and 0 when there is no risk. Risk $k_{i t} \mathrm{t}$ indicates whether the investment income of the $\mathrm{i}$-th investee in the t-round experiment has uncertain risk.

(3) Information disclosure. Information is an important factor that affects market trust. In each round of experiment, whether investors and investees have investment-related information as a measure. The specific information is whether investor A can see the previous round of return amount of investee B and the counterpart's fixed information during investment decision-making Info $o_{i t}$, which is also a dummy variable, recorded as 1 when there is information, and no information Time is 0. Among them, Info $o_{i t}$ indicates whether the $\mathrm{i}$-th person has investment-related information in the t-round experiment.

(4) Control variables. In the process of combing the past research literature, it is found that the gender differences, ethnic differences, and religious beliefs of the participants will all have an impact on the trust experiment (Eckel and Wilson, 2003 ${ }^{[40]}$; Slonim and Guillen, 2010 $0^{[41]}$ ), in order to more accurately study the impact of investment risk and information disclosure on market trust, this article controls other relevant factors. The specific method is to control individual differences in the form of questionnaires before the start of the experiment, including the gender, ethnicity, city or township of the participants, political outlook, parents' highest education level, and whether Have religious beliefs. In addition, the participants' risk aversion and sense of trust are also controlled. Risk aversion is mainly to control the differences caused by the participants' subjective attitudes towards risk. At the same time, the participants' sense of trust is controlled to prevent the level of social trust. The impact of differences on investment behavior.

\subsection{Model setting}

(1) The impact of risk on trust.In studying the issue of investment risk on market trust, this paper conducts risk-free deterministic returns and risky returns random experiments separately by controlling other factors in the experiment to study how investment risks affect trust. Construct models (1a) and (1b) to study this problem from the two dimensions of investors and investees.

$$
\begin{aligned}
& \text { Invratio }_{i t}=\alpha_{i t}+\beta_{i t} \text { Risk }_{i t}+\gamma_{i t} X_{i t}+\varepsilon_{i t}(1 \mathrm{a}) \\
& \text { Retratio }_{i t}=\alpha_{i t}+\beta_{i t} \text { Risk }_{i t}+\gamma_{i t} Y_{i t}+\varepsilon_{i t}(1 \mathrm{~b})
\end{aligned}
$$

Among them, Invratio $i t$ is the ratio of the investment amount selected by the $\mathrm{i}$-th investor in the $\mathrm{t}$-round investment experiment to the initial total amount, and Retratio $_{i t}$ is the amount returned by the i-th investor to the investor in the t-round experiment as a percentage of the income The ratio to the amount. Risk $k_{i t}$ is whether the investment of the $\mathrm{i}$-th investee in the th round of experiment has return risk, it is a dummy variable, and the return has no risk, that is, it is 0 when the return is determined three times, and it is 1 when the return has uncertain risk. . $X_{i t}$ is a control variable related to the personal characteristics of the investor, including factors such as gender, ethnicity and parental education, and $Y_{i t}$ is a control variable related to the personal characteristics of the investor. $\beta_{i t}$ measures the impact of the investment risk in the experiment on the trust between the investor and the investee, and it is expected to be negative according to the previous theoretical analysis.

(2) The impact of information disclosure on trust.Information disclosure can enable investors and 
investees to fully understand market risks and choose investment options suitable for their own risk-taking. The impact of information disclosure on market trust is studied through the following ( $2 \mathrm{a})$ and $(2 \mathrm{~b})$ models.

$$
\begin{aligned}
& \text { Invratio }_{i t}=\alpha_{i t}+\beta_{i t} \text { Info }_{i t}+\gamma_{i t} X_{i t}+\varepsilon_{i t} \\
& \text { Retratio }_{i t}=\alpha_{i t}+\beta_{i t} \text { Info } o_{i t}+\gamma_{i t} Y_{i t}+\varepsilon_{i t}
\end{aligned}
$$

Among them, Info $o_{i t}$ indicates whether the i-th person has investment-related information in the $t$ round of the experiment. It is recorded as 1 when there is information, and 0 when there is no information. The meanings of other variables are the same in model (1).

(3) Regulation of the impact of information on risk. The existence of investment risk will have an impact on market trust, but the risk is usually caused by information asymmetry in the market, information is not fully disclosed, investment risks cannot be fully identified by the market, and risks such as adverse selection are triggered. The protection of self-use will reduce investment willingness and reduce market trust. Therefore, theoretically speaking, through the full disclosure of information, reducing the problem of information asymmetry can reduce the impact of investment risks on market trust. This article conducts empirical research on this process by constructing models (3a) and (3b).

$$
\begin{aligned}
\text { Invratio }_{i t}=\alpha_{i t} & +\beta_{i t} \text { Risk }_{i t}+\varphi_{i t} \text { Risk }_{i t} * \text { Info } o_{i t}+\gamma_{i t} X_{i t} \\
& +\varepsilon_{i t}(3 \mathrm{a}) \\
\text { Retratio }_{i t}=\alpha_{i t} & +\beta_{i t} \text { Risk }_{i t}+\varphi_{i t} \text { Risk }_{i t} * \text { Info } o_{i t}+\gamma_{i t} Y_{i t} \\
& +\varepsilon_{i t}(3 \mathrm{~b})
\end{aligned}
$$

Among them, Risk $k_{i t} * \operatorname{Inf} o_{i t}$ is the interactive item of investment risk and information disclosure, which means that the $\mathrm{i}$-th investor (or the investee) in the t-round experiment has investment risks and information disclosure. In case of simultaneous occurrence, the value is 1 , otherwise it is 0 . The meanings of other variables are the same as in equations (1) and (2) of the model. According to the theoretical information disclosure, the impact on risk has a positive moderating effect, that is, the expected $\varphi_{i t}$ is positive.

(4) The impact of information content. Expected information has a moderating effect on the risk impact, but will it have different effects on different information content? In other words, when the information is disclosed more fully, the degree of market trust is higher, and at the same time, the influence of trust on risk is more significant. The article conducts a more in-depth analysis of this issue, that is, Hypothesis 2b. In the experiment, under different experimental conditions, it is possible to obtain the influence of information content differences while controlling other factors unchanged, so the samples are grouped according to the difference in information content in the experiment, namely, no information group, low information group and high information group. Group, to study the impact differences under different information situations, the specific form is as follows:

Invratio $_{i t}$

$$
\begin{aligned}
& =\alpha_{i t}+\beta_{i t} \operatorname{Inf} o_{i t}+\gamma_{i t} X_{i t} \\
& +\varepsilon_{i t}(4 \mathrm{a})(5 \mathrm{a})
\end{aligned}
$$

Invratio $_{i t}=\alpha_{i t}+\beta_{i t}$ Risk $_{i t}+\varphi_{i t}$ Risk $_{i t} * \operatorname{Info} o_{i t}+\gamma_{i t} X_{i t}$

$$
+\varepsilon_{i t}(4 \mathrm{~b})(5 \mathrm{~b})
$$

Among them, equations (4a) and (5a) have the same regression form as research information disclosure (2), but the difference is that in equation (2), a full sample study is used. The impact of different information content on investors is studied in two sample groups: the high-information group and the high-information group. Models (4b) and (5b) focus on whether there are differences in the market trust shocks of information disclosure with multiple risks under different information content. That is, the more information content, the more obvious the regulatory effect of the trust shocks of multiple risks. According to theoretical analysis, $\beta_{i t}$ and $\varphi_{i t}$ are expected to have greater influence in the group with higher information content than the group with lower content.

(5) Impact of income difference. The study found that listed companies or other investees usually prefer to disclose good news normally, and choose not to disclose or late to disclose bad news, that is, the problem of "reporting good news but not bad news". Therefore, when the income has different conditions, it will affect the information disclosure in the market, and therefore will also cause differences in market trust. Therefore, this paper studies hypothesis $1 \mathrm{~b}$ by constructing a model, that is, whether there is a different impact on market trust under different circumstances. The model is as follows (6), (7) and (8). 
Invratio $_{i t}=\alpha_{i t}+\beta_{i t}$ L. Rate $_{i t}+\gamma_{i t} X_{i t}$

$$
+\varepsilon_{i t} \quad(6 a)(7 a)(8 a)
$$

Retratio $_{i t}=\alpha_{i t}+\beta_{i t}$ Rate $_{i t}+\gamma_{i t} Y_{i t}+\varepsilon_{i t}(6 \mathrm{~b})(7 \mathrm{~b})(8 \mathrm{~b})$

Among them, Rate $_{i t}$ is the rate of return obtained when the investor invests a unit of capital in the i-th person's experiment in round $t$. In this experiment, it is 0 times, 3 times and 6 times, and the probability is one-third of random. L. Rate $i t$ is the value of the rate of return lagging one period, mainly considering that the investor does not know the rate of return of the investment at the initial stage of investment, and will not affect the current investment behavior. The real impact is on The return on investment in the first period, so the return on the previous period is used here. In all models (b), the current rate of return is used because the return ratio of the investee is mainly affected by the current rate of return, so the return rate of the same period is used for regression. Since the main study of the impact of return on market investment trust here, only samples with uncertain returns in the experiment are considered for research. At the same time, the samples are divided into three groups according to the different information content, namely the non-information group, the low-information group and the high-information group. The formula (6) is the non-information group, and the formula (7) is the low-information group and (8) Formula is the regression result of high-information group. The meanings of other variables are the same as above.

\section{RESULT ANALYSIS}

\subsection{Sample statistics}

Based on the selection of the experimental conditions, this article chooses to participate in the experiment as two junior college students in a financial university, a total of 100 people. In the process of combing the past research literature, it is found that the gender differences, ethnic differences, and religious beliefs of the participants will affect the trust experiment. In order to more accurately study the impact of investment risk and information disclosure on market trust, this article Control other related factors. The specific method is to control individual differences in the form of questionnaires before the start of the experiment, including the gender, ethnicity, city or township of the participants, political outlook, parents' highest education level, and whether Have religious beliefs. In addition, the participants' risk aversion and sense of trust are also controlled. Risk aversion is mainly to control the differences caused by the participants' subjective attitudes towards risk. At the same time, the participants' sense of trust is controlled to prevent the level of social trust. The impact of differences on investment behavior. In this paper, 1 round, 6 rounds and 12 rounds of experiments were carried out under each condition. In order to eliminate the bias caused by the first round of experiments and the limited repetition of the last few rounds of experimenters, the sample selected 12 rounds of experiments under each condition The results of the second to fifth rounds of experiments are used as samples to study the problem.

The statistical properties of the main variables are shown in Table 2. The investment ratio is the ratio of the amount the investor chooses to invest in each round of the experiment to the initial amount held by the investor. The return ratio refers to the investment returned by the investor except for the investment received as zero. The proportion of the amount received by the person. The average investment ratio of investors is $58 \%$, and the average return ratio of investees is $39 \%$, which is relatively low. In the investigation of the control variables, it can be seen that the risk aversion is 6.22, indicating that the experimental participants are on average risk aversion, which meets the requirements of general assumptions, and the trust in society can only be said to reach a general level. The ratio of male to female in the experiment was basically the same, mainly from the Han nationality and urban areas, and most of them had no religious beliefs. It shows that through the control variables of these individual characteristics, it is basically possible to control the deviation caused by the experiment participants' differences. 


\begin{tabular}{cccccc}
\hline Variable & Samples & Mean & S.d. & Minimum & Maximum \\
\hline Invratio & 1,208 & 0.58 & 0.45 & 0 & 1 \\
Retratio & 673 & 0.39 & 0.19 & 0 & 1 \\
Risk & 1,208 & 0.50 & 0.50 & 0 & 1 \\
Info & 1,208 & 0.67 & 0.47 & 0 & 1 \\
Risk aversion & 1,208 & 6.22 & 1.55 & 2 & 9 \\
Trust & 1,208 & 5.48 & 1.73 & 0 & 10 \\
Gender & 1,208 & 0.44 & 0.46 & 0 & 1 \\
Nationality & 1,208 & 0.84 & 0.34 & 0 & 1 \\
Urban or Rural & 1,208 & 0.87 & 0.31 & 0 & 1 \\
Political outlook & 1,208 & 0.06 & 0.21 & 0 & 1 \\
Parents' education & 1,208 & 3.14 & 0.68 & 1 & 6 \\
Religious belief & 1,208 & 1.95 & 0.20 & 1 & 2 \\
\hline
\end{tabular}

\subsection{Basic results}

In order to study the issue of investment risk on market trust, this article measures whether there is risk in constructing investment returns. The results of the experiment were compared with risk-free returns and risk-free returns, as shown in Figure 2, which can be seen. When there is no investment risk, investors choose an average investment ratio of $63 \%$. When there is a risk in investment income, the investment ratio drops to an average of $52 \%$. This shows that the existence of investment risk reduces the trust level of investors on average, and the willingness to invest decreases. Similarly, the average return ratio of the investee when there is no risk in the return is $31 \%$. When there is a risk, the return return ratio drops to $13 \%$. In order to further measure the return behavior of the investee, the sample whose investment received by the investor is 0 is eliminated. The return ratio of the investee without risk is $39 \%$, and the return ratio drops to 29 when there is risk. \%. This shows that no matter which calculation method is used, the existence of investment risk not only reduces the willingness of investors to invest, but also reduces the willingness of investors to return returns, leading to a decline in trust in the investment market.

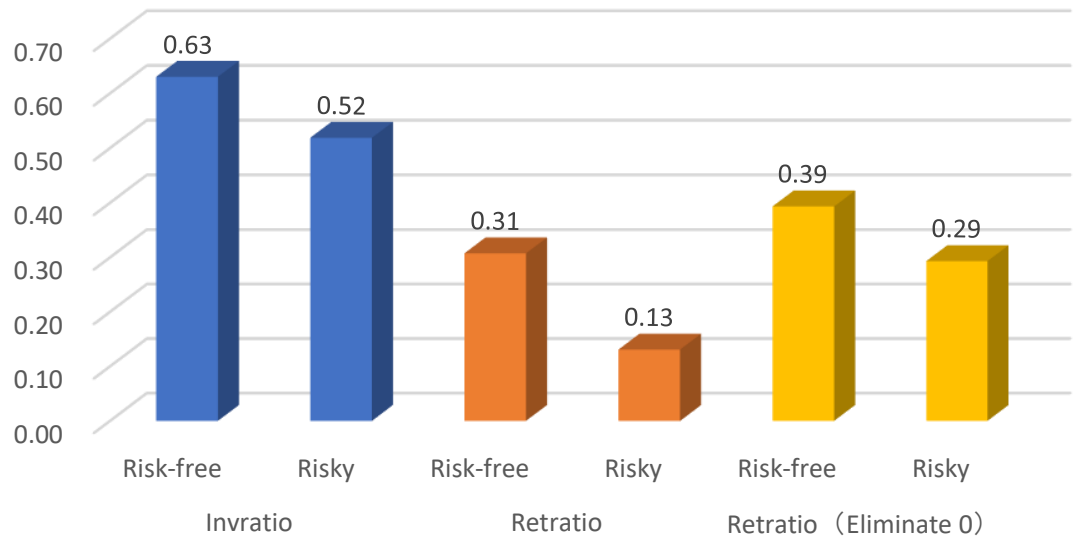

Fig.2: The impact of investment risk on investment trust

In order to study whether the impact of investment risk on investors and investees is significant, the experimental results need to be tested for differences. The results are shown in Table 3. From the overall sample point of view, 
whether it is the investor's investment ratio or the investor's return ratio, the two sets of data have passed the t-test and have significant differences. In addition, this paper also conducts a difference test on the different information content of the experimental samples, and respectively conducts the non-information group, the low-information group and the high-information group when there is investment risk and when there is no investment risk, the investment ratio and return ratio are Difference test. It can be seen that no matter which of the three information groups is, the investment ratio and return ratio under different risk conditions are significantly different. This shows that the existence of investment risk will have a significant impact on the level of trust between investors, and risk will reduce the level of trust between investors, reduce investment expenditures, and reduce the effectiveness of the investment market.

Table 3 Difference test of the impact of investment risk on investment trust

\begin{tabular}{|c|c|c|c|c|c|}
\hline & Variable & Observations & Statistics & $\mathrm{P}$ Value & Conclusion \\
\hline \multirow{3}{*}{ Overall } & Invratio & 604 & 12.02 & 0.0000 & Significant difference \\
\hline & Retratio & 604 & 7.48 & 0.0000 & Significant difference \\
\hline & Retratio (Eliminate 0 ) & 387 & 4.34 & 0.0000 & Significant difference \\
\hline \multirow{3}{*}{$\begin{array}{c}\text { No } \\
\text { information } \\
\text { group }\end{array}$} & Invratio & 208 & 11.70 & 0.0000 & Significant difference \\
\hline & Retratio & 208 & 10.63 & 0.0000 & Significant difference \\
\hline & Retratio (Eliminate 0) & 119 & 6.36 & 0.0000 & Significant difference \\
\hline \multirow{3}{*}{$\begin{array}{c}\text { Low } \\
\text { information } \\
\text { group }\end{array}$} & Invratio & 200 & -3.92 & 0.0000 & Significant difference \\
\hline & Retratio & 200 & -11.30 & 0.0000 & Significant difference \\
\hline & Retratio (Eliminate 0 ) & 84 & -5.37 & 0.0000 & Significant difference \\
\hline High & Invratio & 196 & 17.18 & 0.0000 & Significant difference \\
\hline Information & Retratio & 196 & 20.55 & 0.0000 & Significant difference \\
\hline Group & Retratio (Eliminate 0 ) & 184 & 8.66 & 0.0000 & Significant difference \\
\hline
\end{tabular}

In order to test whether information disclosure can improve market investment trust in the investment process, this paper conducts investment game experiments in the non-information group, low-information group and high-information group. Through the comparison of the experimental results of different information groups, the impact of investment information on market trust is tested. The experimental results are shown in Figure 3 below. The investment ratio of investors increases as the amount of information available increases, and the willingness to invest in the non-information group is only $26 \%$. When there is information, the average investment ratio increases significantly. The investment ratio of investors in the low-information group is $68 \%$, and the investment ratio of investors in the high-information group is as high as $79 \%$. Similarly, with the increase in information content, the willingness of the investee to return is also increasing. The average return ratio of the investee after excluding 0 returns is $21 \%$ in the non-information group and $38 \%$ in the low-information group. When increased, the return rate increased to $44 \%$. This shows that the disclosure of investment-related information can effectively increase the investment ratio of investors and the return ratio of investors, increase market trust, and increase participants' willingness to invest. 


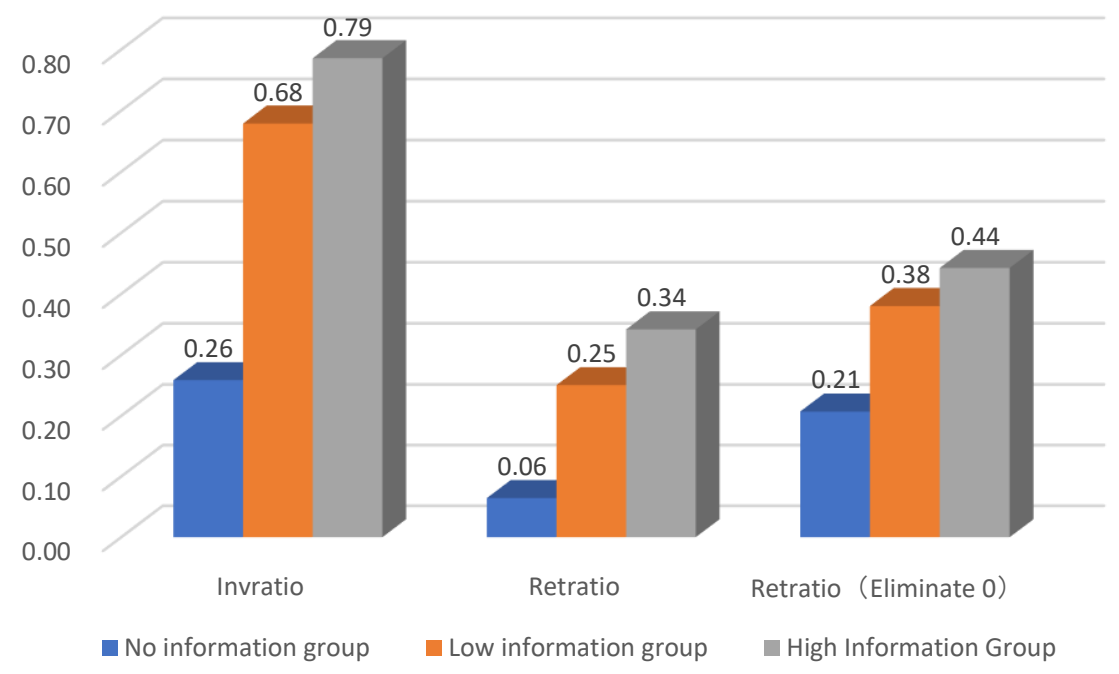

Fig.3: The impact of different information content on investor trust

\subsection{Risk, information and market trust}

The results of the impact of investment risk on market trust are shown in Table 4 models (1a) and (1b). In the regression equation (1a), after controlling the individual characteristics of the experimental participants, the impact of the investment return risk on the investor's investment ratio is -0.106 , which is significant at the $1 \%$ level. This shows that when income is uncertain, investors will reduce the proportion of investment, and the level of trust in the market is declining. Similarly, in the regression equation (1b), it can be seen that when there is an uncertain risk of investment income, and the following does not specify that the return ratio of the investee is zero, the investee will also reduce its own income. The return ratio and the level of trust have declined. It can be seen from the regression equation (1) that when there is an uncertain risk in return, whether it is an investor or an investor, the market trust of both is significantly reduced, and the willingness to invest decreases. Research hypothesis 1a has been verified.

The model of the impact of information disclosure on market trust is (2a) and (2b) in Table 4. From the results, controlling for the differences in individual characteristics, the impact of information on the investor ratio is positive 0.471, indicating that information disclosure has significantly improved Investors' willingness to invest increases investment trust. Similarly, the impact of information disclosure on the proportion of investors returned is 0.202 , which significantly improves the trust of investors. Therefore, the disclosure of investment-related information has increased investors' market trust from both the investor and the investor's side, and increased market activity, proving that Hypothesis $2 \mathrm{a}$ is indeed valid.

Table 4 The impact of investment risk and information disclosure on market trust

(1)

Invratioa
(2)
(3)

\begin{tabular}{|c|c|c|c|c|c|c|}
\hline & Invratioa & Retratiob & Invratioa & Retratiob & Invratioa & Retratiob \\
\hline \multirow[t]{2}{*}{ Risk } & $-0.106^{* * *}$ & $-0.091^{* * *}$ & & & $-0.379^{* * * *}$ & $-0.254^{* * *}$ \\
\hline & -4.04 & -5.70 & & & -10.76 & -7.6 \\
\hline \multirow[t]{3}{*}{ Info } & & & $0.471^{* * *}$ & $0.202^{* * *}$ & & \\
\hline & & & 19.41 & 9.24 & & \\
\hline & & & & & $0.405^{* * *}$ & $0.192^{* * *}$ \\
\hline Risk*Info & & & & & 11.17 & 5.39 \\
\hline
\end{tabular}




\begin{tabular}{|c|c|c|c|c|c|c|}
\hline Risk aversion & 0.014 & 0.004 & 0.012 & 0.006 & $0.019^{* *}$ & 0.005 \\
\hline & 1.46 & 0.82 & 1.51 & 1.16 & 2.15 & 0.90 \\
\hline \multirow[t]{2}{*}{ Trust } & $0.024^{* * * *}$ & 0.000 & $0.017^{* * * *}$ & 0.002 & $0.018^{* *}$ & 0.000 \\
\hline & 3.10 & 0.01 & 2.59 & 0.42 & 2.43 & 0.06 \\
\hline \multirow[t]{2}{*}{ Gender } & -0.002 & -0.016 & -0.003 & -0.024 & -0.007 & -0.011 \\
\hline & -0.08 & -0.93 & -0.10 & -1.47 & -0.24 & -0.64 \\
\hline \multirow[t]{2}{*}{ Nationality } & -0.042 & -0.020 & -0.049 & -0.014 & -0.046 & -0.023 \\
\hline & -1.11 & -1.11 & -1.49 & -0.74 & -1.22 & -1.22 \\
\hline \multirow[t]{2}{*}{ Urban or Rural } & 0.066 & $0.049^{* *}$ & $0.083^{* *}$ & 0.033 & $0.079^{*}$ & $\mathbf{0 . 0 3 8}^{*}$ \\
\hline & 1.40 & 2.08 & 2.08 & 1.55 & 1.74 & 1.65 \\
\hline \multirow[t]{2}{*}{ Political outlook } & -0.060 & $0.062^{* *}$ & -0.063 & $0.055^{* *}$ & -0.103 & $0.062^{* *}$ \\
\hline & -0.88 & 2.08 & -1.09 & 1.97 & -1.53 & 2.31 \\
\hline \multirow[t]{2}{*}{ Parents' education } & 0.028 & $-0.025^{* *}$ & $0.034^{*}$ & -0.015 & 0.026 & -0.016 \\
\hline & 1.37 & -2.19 & 1.92 & -1.51 & 1.36 & -1.49 \\
\hline \multirow[t]{2}{*}{ Religious belief } & -0.065 & -0.047 & -0.107 & -0.030 & -0.081 & -0.043 \\
\hline & -0.92 & -1.55 & -1.60 & -1.01 & -1.22 & -1.50 \\
\hline $\operatorname{Adj} R^{2}$ & 0.0342 & 0.0725 & 0.2632 & 0.1768 & 0.1214 & 0.1166 \\
\hline $\mathrm{N}$ & 1,196 & 673 & 1,196 & 673 & 1,196 & 673 \\
\hline
\end{tabular}

Note: $* * * * *$ and $*$ indicate statistical significance at the $1 \%, 5 \%$ and $10 \%$ levels respectively.

Investment risk will reduce market trust, and information disclosure can increase market trust, but what effect will the interaction of information disclosure and investment risk in investment have on market trust? In other words, risks in the investment market are unavoidable. Is there any way we can effectively reduce the adverse impact of risks on market trust? This paper studies the moderating effect of information on risk by adding interactive items with information in the risk regression. The model is shown in formulas (3a) and (3b) in Table 4 above.

This article will study this issue next. In the previous section, the research found that the external risk of investment damages the mutual trust of all parties involved in the investment market and reduces investment activity. At the same time, investment-related information disclosure can increase trust in the investment market and increase investment. Therefore, this article wants to determine whether investment-related information disclosure can effectively reduce the damage to the investment market caused by income uncertainty. The specifics are as follows (3a) and (3b): from the result (3a), the impact of the investor's investment ratio when there is investment risk but no investment-related information is -0.379 , the coefficient of the interaction term is 0.405 , and when there is information In the case of disclosure, the total impact of risk on investment trust is 0.026 (0.405 minus 0.379), which shows that when there is information disclosure, investment-related information disclosure can effectively reduce the impact of income risk on market trust and increase investors' willingness to invest. In the result (3b), the impact of investment risk on the return ratio of the investee without information is -0.254 , and the interaction coefficient is 0.192 . When there is information disclosure, the total impact of external risk on the return ratio of the investee is -0.062 (0.192 minus 0.254$)$, which shows that information disclosure can also weaken the adverse impact of investment risks on the investor's willingness to return returns. Therefore, it can be seen from the above analysis 
that whether it is the willingness to invest in investors or the willingness to return the returns of the investee, information disclosure can effectively reduce the adverse impact caused by the uncertain risk of investment returns and weaken investment risks. The impact on market trust conforms to the conclusion of Hypothesis 2c. Moreover, the weakening effect of such information disclosure on investment risk is more effective for investors. The impact of investment risk on the investor is weakened from -0.254 to -0.062 , and the impact on investors is changed from -0.379 to positive. 0.026. This shows that when investment risks cannot be avoided, we can reduce information asymmetry by fully disclosing market-related information, thereby reducing the risk of damage to the entire market.

\subsection{The impact of information content}

Information disclosure has a significant effect on market trust and risk adjustment, and further research is needed on the results of different levels of information. This paper builds a model to answer this question in different groups with high and low information content. The specific models are shown in Table 5. Among them, the models (4a) and (5a) have the same regression form as the research information disclosure (2). The difference is that the full sample research is used in the formula (2), and the low information group is used in the formula (4a) and (5a). In the two sample groups of the high-information group and the high-information group, the impact of different information content on investors is studied. It can be seen from the regression results of Table 5 (4a) and (5a) that the regression results of both are significantly positive, which further proves that information disclosure can increase investor willingness and increase trust in the investment market. However, the regression result of the low-information group in (4a) is 0.418 , which shows that even in the case of exchange counterparties, providing investors with the previous round of return information can increase the proportion of investors by $41.8 \%$. But the effect in (5a) the high-information group is more obvious. For every additional unit of information, the investment ratio will increase by 0.52 units, which is higher than 0.418 in the low-information group. This shows that information disclosure can effectively increase the trust of participants in the investment market, and that the more sufficient information disclosure and the more detailed information is included, the greater the degree of trust in participants. It has the same effect on the return ratio of the investee. Considering the length, we will not repeat it.

Models (4b) and (5b) examine whether the effects of different information content on the impact of information adjustment risk are also different, or that the disclosure of investment information can effectively reduce the impact of investment risks on market trust, but the more adequate the information disclosure Whether this weakening effect is also stronger. The samples are grouped according to different information content. The regression results of the low-information group are shown in (4b). The impact of investment risk on market trust when there is no information is -0.265 , and the impact of investment risk when there is information is 0.077 (0.342 minus 0.265) ). The regression results in the high-information group are shown in (5b), the impact of investment risk on market trust when there is no information is -0.302 , and the impact when there is information is 0.151 (0.453 minus 0.302). This shows that whether it is in the low-information group or the high-information group, information disclosure will significantly reduce the impact of investment risks on market trust, and grouping can better illustrate the robustness of the results. At the same time, what I want to prove is that the higher the information content, the more obvious the weakening effect of investment risk impact. In the results of the low-information group (4b), the net effect of the weakening effect of information disclosure on investment risk is about 1.3 times, but in the high-information group (5b), the net effect of the weakening effect of information disclosure on investment risk Is 1.5 times. This shows that information disclosure can not only effectively eliminate the unfavorable impact of investment risks, but also that the more sufficient information disclosure, the stronger the weakening effect of information on investment risks, that is, hypothesis $2 b$ holds. Therefore, in my country's investor market, various investment risks are everywhere. In order to give full play to the productive role of capital and increase the willingness of investment participants, more detailed and standardized information disclosure can be used to weaken the impact of risks. 
Table 5 The impact of different information content on trust

\begin{tabular}{|c|c|c|c|c|}
\hline & \multicolumn{2}{|c|}{$(4)$} & \multicolumn{2}{|c|}{$(5)$} \\
\hline & Invratioa & Invratiob & Invratioa & Invratiob \\
\hline \multirow[t]{2}{*}{ Risk } & & $-0.265^{* * *}$ & & $-0.302^{* * * *}$ \\
\hline & & -6.88 & & -7.93 \\
\hline \multirow[t]{3}{*}{ Info } & $0.418^{* * * *}$ & & $0.520^{* * *}$ & \\
\hline & 14.37 & & 19.65 & \\
\hline & & $0.342^{* * * *}$ & & $0.453^{* * *}$ \\
\hline Risk*Info & & 7.95 & & 11.34 \\
\hline \multirow[t]{2}{*}{ Risk aversion } & 0.008 & 0.015 & 0.006 & 0.015 \\
\hline & 0.79 & 1.35 & 0.60 & 1.48 \\
\hline \multirow[t]{2}{*}{ Trust } & $0.024^{* * *}$ & $0.024^{* * *}$ & $0.029^{* * *}$ & $0.030^{* * *}$ \\
\hline & 2.95 & 2.68 & 3.89 & 3.38 \\
\hline \multirow[t]{2}{*}{ Gender } & -0.013 & -0.013 & 0.009 & 0.010 \\
\hline & -0.38 & -0.34 & 0.30 & 0.30 \\
\hline \multirow[t]{2}{*}{ Nationality } & -0.047 & -0.051 & -0.059 & -0.059 \\
\hline & -1.08 & -1.06 & -1.59 & -1.32 \\
\hline \multirow[t]{2}{*}{ Urban or Rural } & $0.102^{* *}$ & $0.109^{*}$ & 0.049 & 0.036 \\
\hline & 1.99 & 1.92 & 1.22 & 0.69 \\
\hline \multirow[t]{2}{*}{ Political outlook } & -0.068 & -0.086 & -0.022 & -0.115 \\
\hline & -0.98 & -1.10 & -0.30 & -1.27 \\
\hline \multirow[t]{2}{*}{ Parents' education } & $0.044^{*}$ & 0.029 & 0.012 & 0.010 \\
\hline & 1.94 & 1.21 & 0.63 & 0.48 \\
\hline \multirow[t]{2}{*}{ Religious belief } & -0.020 & 0.038 & $-0.180^{* * *}$ & $-0.184^{* * * *}$ \\
\hline & -0.20 & 0.42 & -2.64 & -2.58 \\
\hline $\operatorname{Adj} R^{2}$ & 0.2303 & 0.1029 & 0.3539 & 0.1576 \\
\hline $\mathrm{N}$ & 800 & 800 & 796 & 796 \\
\hline
\end{tabular}

Note: $* * *, * *$ and $*$ indicate statistical significance at the $1 \%, 5 \%$ and $10 \%$ levels respectively.

\subsection{Impact of income difference}

Listed companies usually have a tendency to disclose good news normally, and choose to disclose or postpone the disclosure of bad news. That is, when there is a difference in income, it will affect the information disclosure in the market, which will affect market trust in different ways. Therefore, this article studies hypothesis $1 \mathrm{~b}$ by constructing models (6), (7) and (8), that is, whether there are different effects on market trust under different circumstances. The result of (a) in the model (6), (7), and (8) represents the influence of different return rates on the investor's investment ratio under the control of the difference in information content. The interim formula (6) is the result of no information group, ( 7) is the result of the low information content group, (8) is the result of the high 
information content group. In the non-information group (6a) and the low-information group (7a), the rate of return has no significant impact on the investment ratio, but in the high-information group (8a), the effect of the rate of return on the investment ratio is significantly positive 0.034 . This shows that the impact of investment income risk on investor trust is heterogeneous, that is, the higher the rate of return, the more confidence in investment and the stronger willingness to invest. And, when the information is disclosed more fully, the return rate has a stronger effect on trust. Therefore, just want to increase the participation of market investment by increasing the rate of return on investment, and increasing the trust of investors will not be effective.

The result of (b) in formula (6) (7) (8) represents the impact of different return rates on the return ratio of the investee under different information content. In the case of the non-information group (6b), the rate of return has a significant impact on the return ratio of the investee to 0.008. In the case of the low-information group (7b), the rate of return has a significant impact on the return ratio of 0.033. In the case of group (8b), the effect of the rate of return on the return ratio is significantly 0.055 . It can be seen from this result that when the return on investment is higher and the amount reaching the investee increases, the proportion of the investee returning to the investor will also increase. This shows that the return behavior of the investee is proportional to the amount of investment received. At the same time, it can be found that with the continuous improvement of information content, there are (6b) to (7b), and then to (8b). The information content changes from no information to low information content, and then to high information content. The greater the rate of return, the greater the return The greater the ratio, the more obvious the effect. This shows that the increase in the rate of return can indeed increase the trust level of the participants in the investment market by increasing the proportion of returns by investors, but the disclosure of investment-related information can significantly enhance this effect. This further proves that in the development of my country's capital market, accurate and sufficient disclosure of investment-related information is not only of great significance to increase market trust, but also that information disclosure will strengthen other factors to enhance the role of investment market trust.

Table 6 the impact of yield on investors under different information content conditions

(6)

(7)

(8)

\begin{tabular}{|c|c|c|c|c|c|c|}
\hline & Invratioa & Retratiob & Invratioa & Retratiob & Invratioa & Retratiob \\
\hline \multirow{2}{*}{$\begin{array}{l}\text { Return } \\
\text { Rate }\end{array}$} & -0.019 & $0.008^{* * * *}$ & 0.007 & $\mathbf{0 . 0 3 3}^{* * * *}$ & $0.034^{* * * *}$ & $0.055^{\text {**** }}$ \\
\hline & -1.48 & 2.82 & 0.52 & 7.15 & 2.57 & 11.16 \\
\hline \multirow[t]{2}{*}{$\begin{array}{c}\text { Risk } \\
\text { aversion }\end{array}$} & -0.066 *** & $-0.012^{* *}$ & -0.038 & 0.004 & -0.017 & 0.007 \\
\hline & -2.94 & -2.23 & -1.45 & 0.37 & -0.91 & 0.77 \\
\hline \multirow[t]{2}{*}{ Trust } & $0.067^{* * *}$ & $0.012^{* * *}$ & 0.009 & 0.003 & -0.006 & -0.002 \\
\hline & 4.52 & 3.03 & 0.41 & 0.44 & -0.29 & -0.29 \\
\hline \multirow[t]{2}{*}{ Gender } & -0.110 & 0.003 & $-0.223^{* * *}$ & -0.021 & -0.053 & -0.010 \\
\hline & -1.53 & 0.12 & -2.75 & -0.62 & -0.76 & -0.3 \\
\hline \multirow[t]{2}{*}{ Nationality } & -0.044 & -0.007 & $0.245^{* *}$ & 0.106 **** & 0.053 & 0.051 \\
\hline & -0.4 & -0.26 & 2.05 & 2.88 & 0.49 & 1.19 \\
\hline $\begin{array}{c}\text { Urban or } \\
\text { Rural }\end{array}$ & -0.178 & -0.018 & $0.416^{* * *}$ & 0.079 & 0.114 & 0.015 \\
\hline
\end{tabular}




\begin{tabular}{|c|c|c|c|c|c|c|}
\hline & -1.56 & -0.78 & 5.21 & 1.53 & 0.98 & 0.30 \\
\hline \multirow[t]{2}{*}{$\begin{array}{l}\text { Political } \\
\text { outlook }\end{array}$} & $2.334^{* *}$ & -0.143 & 0.000 & 0.053 & -0.081 & 0.012 \\
\hline & 2.30 & -0.75 & 0.00 & 0.81 & -0.55 & 0.18 \\
\hline \multirow[t]{2}{*}{$\begin{array}{l}\text { Parents' } \\
\text { education }\end{array}$} & $0.075^{*}$ & 0.000 & $0.112^{*}$ & -0.007 & -0.007 & 0.002 \\
\hline & 1.82 & 0 & 1.9 & -0.29 & -0.11 & 0.08 \\
\hline \multirow{2}{*}{$\begin{array}{c}\text { Religious } \\
\text { belief }\end{array}$} & $0.344^{* * * *}$ & 0.043 & $0.524^{* * * *}$ & -0.036 & -0.083 & -0.006 \\
\hline & 2.65 & 1.84 & 3.81 & -0.40 & -0.54 & -0.10 \\
\hline Adj $R^{2}$ & 0.2242 & 0.0979 & 0.2134 & 0.1841 & 0.0782 & 0.3114 \\
\hline $\mathrm{N}$ & 147 & 196 & 147 & 196 & 153 & 204 \\
\hline
\end{tabular}

Note: $* * * * *$ and $*$ indicate statistical significance at the $1 \%, 5 \%$ and $10 \%$ levels respectively.

\section{MAIN CONCLUSIONS}

By extending the classic trust game experiment of Berg et al., this paper studies the influence of investment risk and information disclosure on market trust.It is found that when there are risks in investment, investors' willingness to invest will be significantly reduced, and at the same time, investors' willingness to return returns will be reduced, damaging the trust level of market participants and inhibiting investment. At the same time, the impact of this risk is different at the same time. When the return is high, the inhibitory effect of risk on investment is small; when the return is low, the inhibitory effect of risk on investment will be greater.Further, the influence of different information content of experimental participants on market trust is studied respectively. When there is investment information, the investment proportion of investors increases significantly, and the return proportion of investors also increases.And the greater the amount of information disclosed, the greater the effect. Therefore, the disclosure of investment-related information can effectively improve the level of trust between investment market participants and increase market activity.More importantly, when there is information disclosure, it can effectively reduce the adverse impact of investment risk on market trust.These conclusions are instructive for the improvement of the capital market. In the construction process of China's capital market, it is necessary to establish a standardized information disclosure mechanism to reduce the adverse impact of risks on market trust, so as to give full play to the market's function of efficient allocation of funds.

\section{REFERENCES}

[1] Arrow K E. The limits of organization[M]. Norton, 1974.

[2] Zhang Weiying, Ke Rongzhu. Trust and its interpretation: a cross-provincial investigation and analysis from China $[\mathrm{J}]$. Economic Research, 2002(10): 59-70+96.

[3] Zhao Wenlong, Zhang Ning, Dai Hongjuan. A preliminary study on the logic of market trust and its influencing factors - an empirical analysis based on CGSS2010 data [J]. Journal of China University of Mining \& Technology (Social Science Edition), 2019, 21(01): 54 -66.

[4] Fukuyama, F. Trust: The social virtues and the creation of prosperity[M].New York:Free Press, 1995.

[5] Putnam R. The prosperous community:Social capital and public life[J].The American prospect,1993,13(4):35-42.

[6] Porta R L, Shleifer A,Vishny R W.Trust in Large Organizations[J]. American Economic Review,1997, 87(2):333-338.

[7] Guiso L, Sapienza P, Zingales L. The Role of Social Capital in Financial Development[J]. American Economic Review, 2004, 94(3), 526-556.

[8] Dai Yiyi, Zhang Junsheng, ZengYamin, Pan Yue. Social Capital and Corporate Debt Financing[J]. China Industrial Economics, 2009(08): 99-108. 
[9] Pan Yue, Dai Yiyi, Wu Chaopeng, Liu Jianliang. Social capital, political relations and corporate investment decision-making[J]. Economic Research, 2009, 44 (11): 82-94.

[10] Zhang Xin, Chen Yuzhao. Reform of the U.S. Securities Market Regulatory System and the Reconstruction of the Credit System-Also on the Enron Incident's Enlightenment on the Establishment of the Emerging Securities Market's Credit System [J]. Economic and Social System Comparison, 2002(03): 7-17

[11] Berg J, Dickhaut J, McCabe K. Trust, Reciprocity, and Social History [J].Games Economic Behavior,1995,10:122-142.

[12] Johansson-Stenman O., Mahmud M., Martinsson P. Trust and religion: Experimental evidence from Bangladesh[J].Economica,2008,76(303):462-485.

[13] Cameron, L.Raising the stakes in the ultimatum game:Experimental evidence from Indonesia[J].Economic Inquiry, 1999,37,47-59.

[14] Fehr, E., Fischbacher, U.,Tougareva, C.Do high stakes and competition undermine fairness? Evidence from Russia[J].Working paper series, 2002,ISSN:14240459.

[15] Li Bin, Shi Yupeng, Liu Yanbing. External risk and social trust: Evidence from the trust game experiment $[\mathrm{J}]$. World Economy, 2015, 38(04): 146-168.

[16] Coleman, J. Foundations of social theory[M].Cambridge, MA: Harvard University Press, 1990.

[17] Bolle F. High reward experiments without high expenditure for the experimenter?[J]. Journal of Economic Psychology,1990,11(2):157-167.

[18] Bottom, W. P. Negotiating risk: Sources of uncertainty and the impact of reference points on negotiated agreements[J].Organizational Behavior and Human Decision Processes, 1998,76(2), 89-112.

[19] Sanfey A G, Rilling J K, Aronson J A. The Neural Basis of Economic Decision-Making in the Ultimatum Game[J]. Science, 2003, 300(5626): 1755-1758.

[20] Bottom W P, Holloway J, Miller G J. Building a Pathway to Cooperation: Negotiation and Social Exchange between Principal and Agent[J].Administrative Science Quarterly, 2006,51(1):29-58.

[21] Aghion, P., Algan, Y., Cahuc, P., Shleifer, A. Regulation and distrust[J]. Quarterly Journal of Economics,2010,8,1015-1049.
[22] Li Jinliang, He Chengying, Chen Wei, Chen Rui. Trait risk and the choice of company investment behavior: based on the perspective of the nonlinear relationship between variables[J]. Management World, 2018, 34(03): 68-77.

[23] Li Junqing, Li Shuangjian, Zhao Xuxia. Social trust, rate of return volatility and bank risk[J]. Finance and Trade Economics, 2017, 38(11); 55-69.

[24] Chen Dongyu, Zhu Hao, ZhengHaichao. Risk, trust, and willingness to lend - an empirical study based on registered users of Paipaidai[J]. Management Review, 2014, 26(01): 150-158.

[25] Pan Yu, Zhang Xing, Gao Li. Research on the Factors Affecting Consumers' Purchase Intention in Online Retailing__ Based on the Analysis of Trust and Perceived Risk[J]. China Industrial Economy, 2010(07): 115-124.

[26] Liu Baohua, Luo Hong, Zhou Wei, Yang Xing. Social trust and the risk of stock price collapse[J]. Finance, Trade and Economics, 2016(09):53-66

[27] Li Fengyu, Yang Mozhu. Will economic policy uncertainty inhibit corporate investment? - An empirical study based on China's economic policy uncertainty index[J]. Financial Research, 2015(04): 115-129.

[28] Liu Haiming, Cao Tingqiu. Research on the Impact of Credit Supply Cycle on Enterprise Investment Efficiency-Also on the heterogeneity under the conditions of macroeconomic uncertainty[J]. Financial Research, 2017(12): 80-94.

[29] Botosan C A, Botosan C A,Botosan C. Disclosure level and the cost of equity capital[J]. Accounting Review,1997,72(3):323-349.

[30] Botosan C A, Plumlee M A.A Re-examination of Disclosure Level and the Expected Cost of Equity Capital[J].2002,40(1):21-40.

[31] Sengupta P. Corporate disclosure quality and the cost of $\operatorname{debt}[J]$.Social Science Electronic Publishing, 1998, 73(4):459-474.

[32] Wang Wei, Jiang Gaofeng. Information disclosure, transparency and cost of capital[J]. Economic Research, 2004(07):107-114.

[33] Zhang Chengrui, Wang Hua. The market effect of corporate information transparency: empirical evidence from China's A-share market[J]. China Accounting Review, 2007(01):1-20

[34] Botosan C A, Plumlee M A, Xie Y. The Role of Information Precision in Determining the Cost of Equity 
Capital[J].Review of Accounting Studies, 2004, 9(2-3):233-259.

[35] Lang M H, Lundholm R J. Corporate Disclosure Policy and Analyst Behavior[J]. Social Science Electronic Publishing,1996,71(4):467-492.

[36] You Jiaxing, Jiang Wei, Li Bin. An Empirical Analysis of the Synchronization of Transparency and Stock Price Volatility of Chinese Listed Companies[J]. Zhongda Management Research, 2007, 2(01):147-164.

[37] Zhang Jixun, Zhou Ran, Sun Peng. Disclosure of internal control, audit opinions, investor risk perception and investment decision: An experimental evidence [J]. Accounting Research, 2011(09): 66-73.

[38] Wang Jing, Chen Xiaohong, Yang Li. P2P online lending platform information disclosure level, investor trust and investment risk[J]. China Economic Issues, 2018(03): 106-121.

[39] Eckel C, Tech V. Conditional trust: sex, race and facial expressions in a trust game[J]. University of Texas at Dallas Unpublished,2003,19(4):533-546.

[40] Slonim R, Guillen P. Gender selection discrimination: Evidence from a trust game[J]. Journal of Economic Behavior and Organization,2010,76(2),385-405. 